\title{
TRAPPED BY THE MEDIUM: LANGUAGE AND THE SOCIAL IN RELATIONAL SOCIOLOGY
}

\author{
Marta Bucholc \\ Rheinische Friedrichs-Wilhelms-Universität Bonn \\ University of Warsaw
}

Relational sociology is one of the emergent theoretical trends in contemporary social theorizing. While the most quoted authors on the subject on the internet are Mustafa Emirbayer, the author of a manifesto for relational sociology (1997), and Ann Mische (see Prandini 2015), eminent proponents include Margaret Archer, Pierpaolo Donati, and many others (see, e.g., Dépelteau \& Powell 2013; Fuhse \& Mützel 2013). The question of whether relational sociology should be deemed "a well-defined sociological paradigm or a challenging 'relational turn' in sociology" (Prandini 2015: 1) has not been settled. Nevertheless, it seems beyond doubt that the development of relational theorizing is not the isolated achievement of any single scholar or group of scholars but more a broad tendency to look, once again, at society from a different angle in order better to express our Zeitgeist. There are two features which I find salient in all projects and varieties of relational sociology.

The first is dissatisfaction with the toolbox of extant sociological options, an essential motive to do something new. In the case of relational sociology, this dissatisfaction is roused by the inability of virtually all competing sociological paradigms to cover the gaps in their respective accounts of society successfully. Realization of an inability to make the bridge between methodological individualism, which focuses on individual voluntary action and envisages society as a grouping of individuals, and a more collectivist social theorizing, with its tendency toward a structural, system-oriented methodological holism, is certainly not a novelty in sociological theory, and Margaret Archer has been addressing this problem continuously since her Culture and Agency was published in 1988. If the gap 
between these two general optics is regarded as a result of their respective conceptualizations of the social, then relational sociology would be an attempt to use a different description, one that would magically provide a safe ground for sociology to step onto out of the conceptual chasm.

The second trait of relational sociology is its strong drive to attack the old problem of statics and dynamics again (and to better avail) by translating categories of the social structure into a less ossified conceptual framework without losing the obvious methodological benefit of dissecting the vertebrae of social life. Relational sociology's quest is to save the backbone of the social without fossilizing it: a noble mission, though very likely an impossible one.

As a carrier of our Zeitgeist, relational sociology is accompanied by a number of other theories, whose family resemblance to relational sociology sometimes calls for a high level of expertise in the narcissism of small differences. Nevertheless, relational sociology not only perceives itself as a novelty capable of succeeding where others failed, but also as an alternative to the sociological mainstream, which is usually aligned with a few classical approaches (see Donati 2013: 2). My particular focus is the variant of relational theory put forward since 1983 by Pierpaolo Donati, which he advances as a "critical realist relational sociology" (Donati 2015: 86-87). I address the problem of language as a social materia prima and, in my view, a missing element in relational social ontology. I make my argument by demonstrating that the communicational aspect of social relations calls for linguistic normativity as the basis of all normativity in a society that Archer and Donati call "morphogenic," with morphogenesis being defined as a "process of destructuring in which contingency, complexity, uncertainty and risk are captured by the trope of liquidity" (Donati \& Archer 2015: 5). I commence by a short outline of the context of relational theorizing (for an overview of theoretical affinities see Prandini 2015).

\section{/// Robots in a Maelstrom}

The preliminary questions raised by Donati have considerable bearing for our understanding of the human condition in contemporary societies. This is mostly due to the humane hue of his theorizing, which — though he puts it in rather technical language-probably appeals to every sociologist's heart: 
From the applied perspective, which is oriented towards network intervention, it is a question of producing a change that allows the subjects to manage their own significant, actual and potential relations. They do this by bringing their existing human and material resources-both manifest and latent-into play, so they can achieve an adequate level of self-regulation, or at least sufficient to confront their problems, which would otherwise be perceived and classified as problems of individual actors or of abstract collective entities alone (Donati 2017: 16).

Although this passage only discusses the applied side of Donati's ideas, its meaning can hardly be misinterpreted: it stipulates an agenda for making human lives better by making sociology more adequate. In yet another programmatic statement, another relationist, François Dépelteau, wrote: "sociological explanations are something else than simple stories, descriptions, or language games, even if they take the form of stories, if they are based on descriptions, and if they are made and diffused through languages. It is a praxis related to social relations, to the life experiences of people" (Dépelteau 2015: 52). The two authors are clearly in accord on that point.

An ethical agenda like this opens a vast field of family resemblances between relational sociology and its many antecedents. Two in particular leap to the eye upon reading the above quote: Norbert Elias's figurational theory and Charles Wright Mills' critical sociology.

Let me start with this one short phrase: "an adequate level of selfregulation." Elias explained the development of complex social networks and institutional settings of modern nation states and international structures as both a result of, and a stimulus to, an increasingly strict regime in human self-control, which he termed "civilization" (see Elias 2010, 2012). The production and maintenance of a habitus viable in a complex and highly interdependent society consisted essentially in the long-term elimination of the need to kill all strangers on sight and to discipline nonstrangers by use of direct force. Increasing self-regulation, which is evident in all life-spheres — as demonstrated by Elias's analyses of European manners and standards of politeness evolving throughout the ages toward greater restriction and complication of behaviour-is not only a cultural phenomenon but also a psychological and political one. A new human type is produced as a result of this evolution: one that will insist on using cutlery and handkerchiefs and, as a default rule, on each adult sleeping in a separate bed. All these and similar socially-induced and highly impracti- 
cal needs are supported by feelings of shame, embarrassment, and disgust. It so happens that a human being with such a mental setup usually also makes a reliable taxpayer in the costly structure of a centralized welfare state and a passable voter in a democracy, because shame, embarrassment, and disgust work just as well in politics or the economy as they do in the practices of daily hygiene.

Why is it good for humans to live in a society requiring a high level of self-control and restriction? The analogies between Elias and Thomas Hobbes go deep, for Elias too believed that human life would be utterly miserable without the protection of a complex society and an elaborate normative framework supported by a relatively reliable monopoly of violence (see Wickham \& Evers 2012). But if insufficient self-regulation is the original sin of mankind it is committed out of ignorance, according to Elias. This pertains both to the causes or determinants of human actions and to their consequences. Lack of self-restraint results in reconstruction and, eventually, degradation of networks of interdependence; it poses a threat to higher levels of integration and indeed frequently leads to decomposition. The history of mankind is not only about civilization, but also about de-civilization. Ignorance of the social embeddedness of human actions is also the usual cause of acting in a relatively under-civilized manner, which usually also turns out to be counterproductive.

The picture of a fisherman in a maelstrom, which is used by Elias to depict the tragedy of the human condition (Elias 2007), could well be moderated by another image-Mill's "Cheerful Robot." It is hardly surprising that while a lonesome German Jew who had lived for almost a century came up with the romantic figure of an individual desperately struggling against the hostile elements, a self-proclaimed American Wobbly who only made it to 46 ventured to express the same idea in a metaphor drawing on modern techniques and evoking the nexus of progress, consumerism, and manipulation. A Cheerful Robot is ignorant of its own program, of the algorithms that make it tick, of its interdependence in relations with other robots. But most of all, it is ignorant that whatever problems it may encounter belong to one of two kinds-personal troubles and social issues:

[C]onsider unemployment. When, in a city of 100,000 , only one is unemployed, that is his personal trouble, and for its relief we properly look to the character of the individual, his skills and his immediate opportunities. But when in a nation of 50 million employees, 15 million people are unemployed, that is an issue, and we 
may not hope to find its solution within the range of opportunities open to any one individual. The very structure of opportunities has collapsed (Mills 1959: 9).

Both Elias and Mills believed, though with varying degrees of optimism, that a proper social science could help foster self-regulation and fight ignorance back, all in service of human well-being. Donati also maintains that his theorizing may contribute to the ability to "confront problems" (instead of just dully hurting and suffering), and to link the "problems of individual actors" to those of "abstract collective entities alone." Moreover, he shares Elias's and Mills's conviction that the right way to theorize to this end involves a readjustment of the theoretical apparatus in order to grasp what has been left out of sociology's sight, namely, the connections between humans and the demands they make on human psychology, on the institutional setup of society, and on the structure thereof. We are interconnected creatures who constantly relate to each other, and the path from our problems to our emancipation leads through scientifically informed reflection.

I fully sympathize with Donati's ethical agenda. Elucidating the relational causes of our suffering and inconvenience is a worthy cause. It seems to be a cause particular to a specific type of society, which Donati calls "relational society" and whose emergence is said to have been primarily due to globalization (Donati 2013: 3). Donati claims that relational society is a product of recent social developments, which are unprecedented in human history. This awakens a strong suspicion that a vicious circle is hidden somewhere in his reasoning. If a society is called relational, it stands to reason that relations are very important in this society, but what makes this society more relational than others? The claim needs to be substantiated that it is these relations and nothing else that are very important in the societies covered by Donati's theory (contemporary Western societies, to judge by the choice of empirical illustrations - the re-emergence of religion in the public sphere, the de-rationalization of labour, virtual communities, or the expansion of free giving, see Donati 2013: 3ff.). Offering a fully fledged elaboration on that point would naturally, inevitably, transform Donati's sociology into a comparative historical project-which it is not, contrary to the works of authors following similar paths, such as Norbert Elias or Charles Tilly. However, the step of substantiating the uniqueness of a social form exemplifying the use of relational categories was repeatedly made by some of the first generations of social theorists, to whom we usually 
refer as classics and who did not develop fully fledged historical projects, such as Émile Durkheim or Georg Simmel. Proffering such substantiations enabled the classics to become great without being grand.

\section{/// History as a Remedy against Grand Theorizing}

Aleksander Manterys (Manterys 2017: 78) expressed the view that Donati's theory could be classified as a "Grand Theory" according to Mills. A grand theory was an attempt to cover everything with one huge umbrella hanging high in the air with no visible means of empirical support and irrespective of the weather. I cannot agree that Donati is indeed grand theorizing. Although he certainly strives for universality and generality, I do not see the fault in this as long as the universality and generality are limited to one line of historical societies, not unlike the one in which we happen to be living.

Donati shares some of the concerns of those thinkers whose goal it was to establish sociology as a specialized social knowledge of some consequence. Two in particular seem highly relevant in this respect: Émile Durkheim and Georg Simmel, though Donati's affinity to Simmel seems more clearly marked. What they all have in common is a focus on the structural effects of what happens between interacting humans, as well as a deep conviction that the societies which they happened to study were both historically unique and informative of the nature of societies in general. For this reason, I believe Durkheim and Simmel may be looked to in searching for what is missing in Donati's writings: a historical reason for the theoretical priority of relations.

Both Durkheim and Simmel were anti-reductionists. The former safeguarded society's status as a sui generis reality and thus foreclosed the field of sociological explanations of social facts. The latter, though prone to psychologism, insisted on the role of social forms as the historically stable objects of research of this truly specialized science of sociology of which, according to himself, he was the only representative. Both social facts and social forms were the fabric of social life as such, present in every conceivable society as its defining characteristics. However, both Durkheim and Simmel, though constructing a universal and general theoretical apparatus, also insisted on the need for an overview of social change. Durkheim referred to simple societies in order to explain the complexity he saw around himself. As part of a thought experiment consisting in imagining science, economics, society, art, religion and so on before the crisis, Simmel de- 
plored the crisis of European culture. Durkheim's concept of rampant individualization as a new basis for social integration in modern industrial societies was as much a conclusion drawn from a comparison with an imagined pre-industrial society as Simmel's description of a metropolis was an exercise in participant observation.

This heuristic strategy of sociology was best explained by another author, Max Weber, who took a very different path from both Simmel and Durkheim. In an introductory remark to his study of bureaucracy he wrote: "Es wird hier absichtlich von der spezifisch modernen Form der Verwaltung ausgegangen, um nachher die anderen mit ihr kontrastieren zu können" (Weber 1980: 125). What he meant was this: we have to start with a datum in order to compare and to generalize. We do know our own society and can apply ideal types based on this knowledge as heuristic instruments to be used in other contexts. Even though this operation is a trick, we should never give it up. Otherwise, the causal links and relations of meaning observed in our empirical material may turn out to be nothing but artifacts of our method: we see what we know, but we fail to know what it is that we see.

Weber, being concerned with the objectivity of the social sciences, suggested a methodological self-alienation: a procedure which I find is admirably - though inadvertently_applied by Durkheim and Simmel, but is absent in Donati's work. Thus Donati certainly manages to avoid being grand in the pejorative sense, but he also unnecessarily narrows the scope of application of his own theory. It would seem that the desire to eliminate certain threats, in particular that of reductionism, makes Donati imperceptive of other issues, and this hampers the universality of his theory by making it more embedded in the bic et nunc than most classical theories ever were, and less sensitive to the generalities behind it. Therefore, even though Donati is vocal about the emancipatory potential of his theorizing, its actual critical edge seems less well vetted than it deserves to be.

\section{/// The Signs of the Unspoken}

I will offer but a few examples of those limitations to Donati's theorizing which I find particularly thought-provoking in regard to its scope of application, and with which I am concerned precisely because I share Donati's ethical agenda. They all fall into the class of what I would call "the signs of the social." Donati insists that the reality made by interacting hu-

mans (not of them) is "invisible, unspoken, and often uncertain" (Donati 
2017: 18). This "unspoken" is, however, not unspeakable, provided we have a key to decipher its meaning. Much as the god of old in Delphi, it speaks to us through ambivalent signs to which the art of sociological divination must be applied. The social has to be divined out of our social life, where there are signs to be read using the relational methodology.

The first and the most important sign of the social is language. In many instances, Donati uses our manner of speaking about the world as an argument to support his theses. This could be disregarded as an illustration of minor bearing if it was not so ubiquitous in his writing.

Thus when he notices that "we see individuals but we speak on the suppositions of relations" (Donati 2017: 27), he presupposes two things: first, that we indeed do see the individuals, and second, that while relating these perceptions, we suppose the relations between the individuals. Neither of these two presuppositions is unproblematic. On the one hand, it may be argued that the relations are part of our perception — not because they are observable but because our cognitive routine builds them into our perception so as to make them an inextricable part of what we speak. This may well result from our linguistic habits, but there is no reason to assume that these habits tell us anything about the way the world is-without a strong set of additional preconditions being fulfilled, including a correspondence between human mentality and the organization of the world. There are theories which cover these preconditions and account for the correspondence between the world, language, and the human mind; some of them, to mention just John Searle's, have been subject to Donati's scrutiny (see Donati \& Archer 2015: 43ff.). Instead, Donati here quotes the second philosophy of Ludwig Wittgenstein, an important philosopher for relationist theorizing (see Crossley 2015). This reference suggests no correspondence at all between the world and the language, though; it only suggests that language games may exist in which an assumption of such correspondence is part of the rules, just as the assumption of the house not imminently falling on our heads is part of our form of life as house-dwellers.

An equally problematic remark concerns the use of personal pronouns. Donati argues that "every mode of being a self (as I, Me, We, You) is a dialogue (an internal conversation) with the subject's 'I'. The battlefields are everywhere." (Donati 2017: 54). Personal pronouns are of great sociological import, as they are indeed ways of expressing relations to other people that are not concretized, as use of proper names would be, but generalized and indicative of the ways in which these relations are conceived of as modalities of social relations and not as their exemplifications. Similar analy- 
ses of the modalities of language have been conducted using a relational paradigm (see Fontdevila \& White 2013). If Donati's point were limited to this observation, I would, of course, concur. To name just one classic example: Elias discussed personal pronouns in What is Sociology? and insisted that it was their generality and relationality which made them such useful tools for referring to other individuals within the figuration (Elias 2012b: 117ff.). Elias also used the example of the pronouns "I," "you," "he," "she," "we" and "they," correctly insisting that they can be used to represent the individuals' respective positions and articulate their interconnectedness, because each of them (as is the nature of all pronouns) can only be used meaningfully in the context of other positions.

As occasional expressions, the personal pronouns change their referents, which points to their affinity with the dynamic and changeable nature of the figurations. However, if occupying a certain social position were treated as a mode of the "self," and such self were construed dialogically, according to the personalist approach which seems to underpin Donati's argument, then these modes of the self need not necessarily be expressed linguistically as personal pronouns (or, indeed, expressed at all). Furthermore, some modes of the self could be expressed in a different manner altogether. "Is the Relational Subject singular, plural or both?" Donati and Archer once asked (2015: 80), but there are so many other possibilities... For example, to use diverse proper names describing the same individual depending on the typified context is also an option, and a far less confusing if more memory-straining one. Finally, it may be argued that personal pronouns, though undoubtedly facilitating dialogue, at the same time deprive it of the personal element, for they reduce the person to an aspect bearing on the pragmatic context of the pronoun use. Archer and Donati have noted this aspect of personal pronouns in the past: "in ordinary life, we, qua individuals, often speak in the plural referring to a 'We.' (...) Referent remains unspecified and serves only to indicate who was involved in an event: what constitutes a we" (Donati \& Archer 2015: 33). But none of us is a "we," even though at times we all happen to be referred to as a "we," or "you," or "her": it is hard to draw a valid argument about interactional reality from the fact that certain occasional expressions in a certain language tend to come in only so many distinct variants in two grammatical numbers.

The strength of Donati's argument depends-contrarily to the arguments of philosophers such as Martin Buber (see Donati \& Archer 2015: 69), who also used the terminology of personal pronouns- on the lin- 
guistic reality and not on philosophical statements about human nature. To conduct an internal dialogue from which a mode of myself as a "you" emerges, I need to operate the concept of a "you," which translates into my use of a personal pronoun and is evidenced empirically by the same. If there is no empirical, linguistic "you," the internal dialogue cannot constitute it, either. To imagine a language without personal pronouns means, according to Wittgenstein's famous dictum, imagining a form of life (Wittgenstein 1986: par. 241). But it is difficult to state with certainty in what way such other form of life would differ from ours. Even the universality of the "I" and the "me," as basic self-reference structures for the self and a basic tool to be used in dealing with the world and relating to others, may be challenged for societies marked by a very low level of individuation or individualization. Of course, Donati's theory pertains, in its core, to societies in which Indo-European languages are predominantly spoken, which makes it difficult to ascertain the level of generality of his statement about the modes of the self and their link to personal pronouns in the ordinary language.

Another of Donati's arguments concerns the way we use the word "love." In a passage concerning AGIL, Donati argues by way of supplementary explanation that when formulating statements regarding very different things (such as loving a dog and loving a man) we grasp relational analogies between the apparently diverse situations using similar words (Donati 2017: 45). It is a Simmelian argument, because it essentially consists in extracting the "relational" moment out of our everyday speech, just as Simmel would suggest extracting the religious moment or the secrecy moment out of our daily behaviour. However, while the religious moment was an intrinsic aspect of the situation perceivable to a social thinker who had a preconceived idea of religiosity — a component and not a sign of any substantive religion behind it-Donati seems to suggest that our manner of speaking is indicative of the existence of relations: they must be there, for why else would we mention them? Such reasoning, though forensically persuasive, is not convincing.

A famous quote from Wittgenstein seems fitting here:

One can imagine an animal angry, frightened, unhappy, happy, startled. But hopeful? And why not? A dog believes his master is at the door. But can he also believe his master will come the day after tomorrow?-And what can he not do here?-How do I do it?How am I supposed to answer this? Can only those hope who can 
talk? Only those who have mastered the use of a language. That is to say, the phenomena of hope are modes of this complicated form of life. (If a concept refers to a character of human handwriting, it has no application to beings that do not write.) (Wittgenstein 1986: 174).

This passage, which is usually called upon by those interested in Wittgenstein's view of the animal mind, also speaks of the limitations of human language. Donati is making a general claim that the way people declare relations to exist by naming them in their speech is a sign of the things relating. But in some languages (or in some imaginable languages) it may not be possible to say that one loves a dog, or indeed, a man. In some languages these relations may be covered by different concepts, designated by different expressions and bearing no resemblance at all. Even though it would be very hard to imagine a language in which some words would not be used as functions (such as "to love") whose arguments are taken from a pool of words designating objects in the real world (such as "a dog" or "a man"), it is not impossible. Moreover, if we compare distinct ethnic languages, the layout of the relations designated by such sentence functions may be surprisingly different. To give but one example: in English one can "destroy" a dog, whereas the latter action in Polish is referred to, literally, as "putting the dog to sleep"- - the same expression one would use in a sentence involving a baby. It is risky to read words as signs of relations if we do not wish to narrow our field to a single ethnic language-which is often the case with (predominantly) English-speaking analytical philosophy but which should not be the fate of sociology.

It is not my goal here to offer a simplistic rendition of the Sapir-Whorf hypothesis. I merely intend to demonstrate that an argument drawing on the way in which we speak, unless treated very lightly, is only limited to those of us who do indeed speak in a certain manner or, in Wittgenstein's parlance, share a "form of life." A good point is made by Thomas Luckmann (1970), among others, that humans can meaningfully relate to things which are not only non-human but also inanimate from the viewpoint of certain other humans, and can represent these relations in their respective languages. We do, indeed, live in many different worlds, despite the fact that, according to John Searle, we all live in one (2010).

I do not mean to say that using an illustration from an ethnic language should be banned from sociology. But it would be more useful, in my opinion, to steer toward those theories of the social that address the problem of 
the ontological involvement of language or, better still, the linguistic nature of social reality. I find this approach fruitful as far as it combines three things which Donati fails to interconnect in his rich theoretical imaginary: language, social relations, and normativity.

\section{/// The Relational Creation of Normativity}

The problem of normativity, or-more precisely_of norm/rulemaking and norm/rule-following in society plays an important role in Donati's description of relational society. When characterizing the "fourth paradigm" of sociology, which he advocates, Donati writes:

Such a paradigm:

a) recognizes that the 'systemic-normative coherence' of the first two systems paradigms (Durkheim's structure of the whole and the part, and Parsons's system/environment) cannot explain the advent of a morphogenic society; contemporary society is intrinsically characterized by the loosening and fragmentation of social relations, with the ending of socialization through internalization of norms; (...)

d) interprets the new normative order of the morphogenic society as the coming up of social networks run by a situational logic of opportunities ('a relational logic of networks') which is, at one and the same time, strategic (cognitive and instrumentally-driven), communicative (expressive and dialogical), and normative (based on generalized values) (Donati 2017: 36). ${ }^{1}$

A morphogenic society is one in which the societal formation is openended due to a "situational logic of opportunities." This concept of Archer's refers to the same kind of societies which Donati christened "relational," therefore it would not be unfair to read the above remarks regarding normativity in a morphogenic society as referring to a relational society. The initial point about the end of socialization through the internalization of norms raises the question of alternative modes of socialization.

First of all, though it does not seem that the old modes of socialization are completely absent from a morphogenic society-at least inso-

\footnotetext{
1 References in the original have been omitted.
} 
far as certain old-time institutions such as nunneries, schools, and mafias persist within its framework- the point Archer is making seems accurate inasmuch as it addresses the question of permanent belonging. Archer once wrote that "socialization can no longer be credibly conceptualized as a largely passive process of 'internalization' because there is less and less to normalize - that is, to present as being normal and normatively binding" (Donati \& Archer 2015: 127). Normality happens less often in a morphogenic society, as a result of the "loosening and fragmentation of social relations." It could be argued that an individual exposed to the temporary influence of a socialization milieu that is limited upfront and is not exercised throughout all spheres of life is not socialized in the same manner as a person subjected to consistent and continuous socialization pressure in all spheres of life. Surely both modes of socialization are but ideal types and the question is which of them prevails in concrete socialization processes in a particular society. The remark on the normative aspect of the situational logic of opportunities is enlightening in this respect: it rests on "generalized values," which seem to refer to a form of axiological consensus on the social scale, and, by consequence, on the equation of normality and normativity.

It follows that the less axiological consensus can be found in a society, the weaker will be the normative dimension of the situational logic on which the normative order of the morphogenic society is founded. However, if I read the above-cited passage correctly, it does not necessarily mean that the normative order must be weakened too: the meager normative consensus may be compensated for by its "strategic (cognitive and instrumentally-driven)" and "communicative (expressive and dialogical)" aspects. The three are interrelated, but they need not be equally well developed in any empirical normative order. This brings us to the problem of language in the process of normativity production. The loosening and fragmenting of social relations does not mean that they are less expressive and dialogical-quite the contrary. A morphogenic society is described as displaying greater emancipation potential than its predecessors, which is also evidenced by the fact that individuals are subjected to less socialization pressure and internalize less. That, however, does not explain the conditions for the possibility of communication in such a society. Even though the institutionalized normative orders may not be internalized in a manner typical of previous social forms, the language of communication is still a forced communication medium. Moreover, insofar as communication must make up for the weaknesses of normative consensus, it can be 
assumed that more communicational competence on the part of individuals is needed in order to maintain the normative order of a morphogenic society. People in networks need to communicate more in order to relate to one another effectively in the absence of other linkages, including various forms of permanent common belonging which could provide a common base for a normative consensus.

Donati emphasizes networking processes as a self-standing source of socialization and defends sociology against reductionism. However, I believe that a risk of linguistic reductionism is produced as a result of this defense. What is the substance, the materia prima, of social relations? If the rules are made situationally and opportunistically, why are they followed? One could use Searle's expression to say that somebody just "gets away with it" and manages to establish the rule because it is followed, and the rule only exists inasmuch as it is actually followed. Rule-following is a fact, which can be detected by observation, but the making of this fact is essentially linguistic. How and why do individuals follow rules which are made as we go along, as Wittgenstein said? Is the opportunistic situational rule-making enough to open the black box of the normative, described by Stephen Turner (2010)? I am not convinced that is the case, but even more do I doubt that normativity can be explained if due attention is not given to linguistic socialization in a morphogenic society.

I would argue that in the networks of a morphogenic society linguistic socialization takes the place of other forms of socialization as a basis for relating to others, and that socialization provides individuals with the basic rule making-competence from which the fact-making capacity of creating the social world by word is derived. The social world resists attempts to change it because of the resistance of the linguistic fabric from which it is made. Such an approach corresponds well with Donati's view on creativity in a relational society, which is connected to the issue of contingency and freedom: "Society (which is relationality) is surely a contingent reality, but contingency does not mean pure accident. It is in fact the notion of contingency which is in need of new semantics" (2017: 55).

The concept of the situational logic of relations allows for free human creativity, which makes the world as it is. The world could be different but is not-somebody got away with it, endowing the actualized world with accidentals which do not belong to its nature but, in the order of our cognition, make it what it is for us. To come back to the scholastic and Aristotelian roots of the notion of contingency: the shape of the world is accidental, and not transcendental and universal, but the notion of accident 
(making for a contingent entity) only makes sense if there is also something non-accidental, a foundation on which the accidents can differentiate beings. Unless we can demonstrate or assume that there is something like that somewhere there, we are only contending that everything could be different but is not-which makes the whole social network an accident (or, indeed, a coincidence), on a huge scale, but contingent on nothing. If we wish to avoid some very obscure metaphysics, we had better opt for a very simple candidate for the social materia prima. I would argue that the social world as envisaged by relational sociology is contingent on the process of linguistic rule-making: not on any particular rule which may be internalized in any particular manner, but on the making, as a process which Donati describes by referring to the game metaphor.

\section{/// Conclusion: Playful Relations}

Donati insists that a social relation is not a pure game:

One cannot say of it what Wittgenstein (1979) said of the linguistic game in his essay On Certainty: 'Something unforeseeable... I mean it is not founded, it is not rational, or irrational. It is just there like our life...' That social relations follow vague, fuzzy, or ambiguous rules, forms part of our common everyday experience, as does our tendency to polarize - to think in binary codes: inside-outside, symmetric-asymmetric, which is the easiest way of simplifying reality. But social relations cannot be structurally uncertain, ambiguous, or dichotomous in the long run (Donati 2017: 61).

Relations are not unforeseeable, because they have structures. Even though they are contingent, they are not arbitrary und volatile, because their structures are rooted in the normativity of language games. It is a particular normativity, for it is at the same time imperative and uncodifiable. It is not solely the way we experience the world that makes it so fuzzy: relations can not be otherwise, because for every rule that has successfully been made, realized, and actualized according to Searle's prescription of "getting away with it," there is a vast (indeed infinite) logical continuum of possible yet unrealized alternative rules. Therefore, unless we want to confront the Charybdis of reductionism while avoiding the Scylla of systemic normative coherence, it can safely be said that the structures of social relations are normatively prescribed (even by the opportunistic, situ- 
ational logic of rule-making), and maintained linguistically by force of the elementary normativity which underpins the rule-governedness of human language.

I would oppose the contention that "norms and rules are a necessary and inevitable way of regulating, under normal conditions, the contingency of situations that are not socially predetermined" (Donati 2017: 61). Apart from the reservation regarding normal conditions, which may refer to the mental health of the social actors as well as to the pace of social changeto raise just these two possibilities - this latter sentence is in fact a post hoc, ergo propter hoc explanation. It is inferred here from the existence of the rules that there are contingent situations which are not socially predetermined and need to be regulated, because we see that they display regularities, while it remains our theoretical assumption that they need not do so. And it is a fact that they need not display any particular complex of regularities, but they have to remain rule-governed to the degree necessary to maintain the linguistic fabric of relations. Wittgenstein also said that there are many games, and some of them are more orderly than others, but he never claimed that all human behaviour is rule-governed. Not all regularity and, by consequence, not all normality is normative, however weak a meaning we might wish to assign to the notion of normativity. But without any form of internalized normativity no structure can be maintained.

The communicational competences of individuals, which do not feature much in relational sociology accounts, seem to operate as a toolbox enabling individuals to relate to one another, to be creative, to actualize various potentialities of the social, and to play games, which all rely on the basic skill I once christened the "player's attitude" (Bucholc 2015). To claim that language is an important determinant of social relations and, by extension, social reality, including relational theorizing, may be yet another instance of what François Dépelteau christened "theoretical co-determinism" (2008). Nevertheless, it seems worthwhile to bear in mind that relational subjects are players, and their playfulness stems from the language they are using to maintain the existence of their playground.

Acknowledgments:

The author acknowledges the support of Polish National Science Centre (project no. 2014/13/B/HS6/03741). 
Bibliography:

/// Bucholc M. 2015. A Global Community of Self-Defense: Norbert Elias on Normativity, Culture, and Involvement, Klostermann.

/// Crossley N. 2015. Relational Sociology and Culture, "International Review of Sociology", vol. 25(1), pp. 65-85.

/// Dépelteau F. 2008. Relational Thinking: A Critique of Co-deterministic Theories of Structure and Agency, "Sociological Theory", vol. 6(1), pp. 51-73.

/// Dépelteau F., Powell C., eds. 2013. Applying Relational Sociology: Relations, Networks and Society, Palgrave Macmillan.

/// Donati P. 2013. Relational Sociology and the Globalized Society, [in:] Applying Relational Sociology: Relations, Networks and Society, eds. F. Dépelteau, C. Powell, Palgrave Macmillan, pp. 1-24.

/// Donati P. 2015. Manifesto for a Critical Realist Relational Sociology, "International Review of Sociology", vol. 25(1), pp. 86-109.

/// Donati P. 2017. Relational Versus Relationist Sociology: A New Paradigm in the Social Sciences, "Stan Rzeczy”, vol. 12(1), pp. 15-66.

/// Donati P., Archer M. 2015. The Relational Subject, Cambridge University Press.

/// Elias N. 2007. Involvement and Detachment, transl. E. Jephcott, ed. S. Quilley, University College Dublin Press.

/// Elias N. 2010. Humana Conditio, [in:] Norbert Elias: The Loneliness of the Dying, and Humana Conditio, transl. E. Jephcott, eds. A. Scott, B. Scott, University College Dublin Press, pp. 77-170.

/// Elias N. 2012a. On the Process of Civilisation: Sociogenetic and Psychogenetic Investigations, transl. E. Jephcott, eds. S. Mennell, E. Dunning, R. Kilminster, J. Goudsblom, University College Dublin Press.

/// Elias N. 2012b. What is Sociology?, transl. G. Morrissey, S. Mennell, E. Jephcott, eds. A. Bogner, K. Liston, S. Mennell, University College Dublin Press.

/// Emirbayer M. 1997. Manifesto for a Relational Sociology, "American Journal of Sociology", vol. 103(2), pp. 281-317. 
/// Fontdevila J., White H.C. 2013. Relational Power from Switching across Netdoms through Reflexive and Indexical Language, [in:] Applying Relational Sociology: Relations, Networks, and Society, eds. C. Powell, F. Dépelteau, Palgrave Macmillan, pp. 155-179.

/// Fuhse J., Mützel S., eds. 2013. Relationale Soziologie, Springer VS.

/// Luckmann T. 1970. On the Boundaries of the Social World, [in:] Phenomenology and Social Reality: Essays in Memory of Alfred Schütz, ed. M. Natanson, Nijhoff, pp. $73-100$.

/// Manterys A. 2017. Relational Sociology Paradigms, "Stan Rzeczy", vol. 12(1), pp. 67-94.

/// Mills Ch.W. 1959. The Sociological Imagination, Oxford University Press.

/// Prandini R. 2015. Relational Sociology: A Well-Defined Sociological Paradigm or a Challenging 'Relational Turn' in Sociology?, "International Review of Sociology", vol. 25(1), pp. 1-14.

/// Searle J. 2010. Making the Social World: The Structure of Human Civilization, Oxford University Press.

/// Turner S.P. 2010. Explaining the Normative, Polity Press.

/// Weber M. 1980. Wirtschaft und Gesellschaft. Grundriß der verstehenden Soziologie, Mohr.

/// White H.C., Godart F.C. 2013. Relational Language: The Example of Changes in Business Talk, [in:] Relationale Soziologie, eds. J. Fuhse, S. Mützel, Springer VS, pp. 273-289.

/// Wickham G., Evers B. 2012. Elias in the Footsteps of Hobbes?, "Human Figurations", vol. 1(1), http://hdl.handle.net/2027/spo.11217607.0001.106, accessed 10.08.2017.

/// Wittgenstein L. 1986. Philosophical Investigations, transl. G.E.M. Anscombe, Blackwell. 


\section{/// Abstract}

This paper discusses the philosophical background and socio-theoretical affinities of Pierpaolo Donati's relational sociology, focusing particularly on language as a missing element in relational social ontology. Following a discussion of Norbert Elias's and Charles Wright Mills's ideas of modernity as a counterpart to Donati's theorizing, the paper criticizes the concept of relational society and the limitations to its applicability. The author argues that the communicational aspect of social relations calls for linguistic normativity as the basis of all normativity in a society that Margaret Archer and Donati call "morphogenic."

Keywords:

relational sociology, sociological theory, language, Donati Pierpaolo, Wittgenstein Ludwig

/// Marta Bucholc - works at the University of Bonn and the University of Warsaw. She obtained her habilitation (2014) and her Ph.D. (2006) in sociology at the University of Warsaw. She graduated in sociology, philosophy, and law from the University of Warsaw. Her research focuses are the history of social theory, sociology of law, and sociology of knowledge. Her recent books include Sociology in Poland: To Be Continued? (2016), Piaty wymiar (2016) and Global Community of Self-Defense (2015). She has translated several books into Polish, including The Sociological Imagination by Charles Wright Mills, Purity and Danger by Mary Douglas, and Le Temps de Tribus by Michel Maffesoli. She also edited the first full Polish translation of Norbert Elias's On the Process of Civilisation.

E-mail: mbucholc@uni-bonn.de 
